\title{
A singularidade que cuida como conceito ferramenta na arte de partejar: narrativas
}

\section{de parteiras tradicionais}

\author{
The singularity that cares as a concept tool in the art of midwifery: narratives of traditional
} midwives

\section{La singularidad que cuida como herramienta conceptual en el arte de la partería: relatos de} parteras tradicionales

\section{Resumo}

Objetivo: Apresentar ações e arranjos de parteiras tradicionais na conformação do cuidado em uma região amazônica, usando como fio condutor suas narrativas sobre o contexto do partejar. Método: Investigação qualitativa descritiva com 15 parteiras tradicionais, nos anos de 2015 e 2016, desenvolvida por meio de entrevistas e elaboração de diário de campo. A construção das narrativas teve Walter Benjamim como base teórica e metodológica. Resultados: As narrativas expressam afetividade e construção de subjetividade entre parteiras e parturientes, a afirmação dos saberes produzidos entre mulheres, a relação natural com o corpo grávido e a construção de autonomia, cuidado e apoio à pessoa que é partejada. Considerações finais: A singularidade é um conceito ferramenta na arte de partejar que aponta para a não objetivação dos corpos, para os deslocamentos que passam pelo território dos afetos, para as relações construídas entre parteira e parturiente e para a construção de subjetividade e autonomia nos modos de andar a vida.

Palavras-chave: Cuidado de saúde; Parteiras; Narrativas; Gestante.

\begin{abstract}
Objective: to present actions and arrangements of traditional midwives in the conformation of care in an Amazon region, using their narratives about the context of midwifery as a common thread. Method: Qualitative descriptive research developed through interviewing 15 traditional midwives between 2015 and 2016 and a field journal to support registering the information collected. The construction of the narratives had Walter Benjamin as a theoretical and methodological basis. Results: the narratives express affectivity and construction of subjectivity between midwives and parturients, the affirmation of knowledge produced among women, the natural relationship with the pregnant body and the construction of autonomy, care and support to the person who is parturient. Conclusion: singularity is a concept that is a tool in the art of midwifery that points to the non-objectification of bodies, to the displacements that go through the territory of affections, to the relationships built between midwife and parturient woman and to the construction of subjectivity and autonomy in the ways of walking through life.
\end{abstract}

Keywords: Health care; Midwives; Narratives; Pregnancy.

\section{Resumen}

Objetivo: Presentar las acciones y arreglos de las parteras tradicionales en la conformación del cuidado en una región amazónica, utilizando sus narrativas sobre el contexto de la partería como hilo conductor. Método: Investigación cualitativa descriptiva con 15 parteras tradicionales, en los años 2015 y 2016, desarrollada a través de entrevistas y elaboración de diarios de campo. La construcción de las narraciones tuvo como base teórica y metodológica a Walter Benjamin. Resultados: Las narrativas expresan la afectividad y la construcción de la subjetividad entre parteras y 
parturientas, la afirmación del conocimiento producido entre las mujeres, la relación natural con el cuerpo gestante y la construcción de la autonomía, el cuidado y el apoyo a la persona parturienta. Consideraciones finales: La singularidad es un concepto que es una herramienta en el arte de la partería que apunta a la no objetivación de los cuerpos, a los desplazamientos que atraviesan el territorio de los afectos, a las relaciones que se construyen entre la partera y la mujer parturienta y a la construcción de la subjetividad y la autonomía en las formas de caminar por la vida.

Palabras clave: Cuidados de la salud; Partería; Narrativa; Embarazo.

\section{Introdução}

A experiência com o parto remete a uma composição intrinsecamente ligada às mulheres, aos seus vínculos e suas famílias. No Brasil, essa prática social sofreu as influências sócio-históricas do século XIX, quando a medicina moderna deslocou da casa para o hospital a assistência à mulher durante o parto e o nascimento, sob a alegação de o ambiente hospitalar ser mais seguro pela lógica do risco de morte para a mãe e o bebê. Novas técnicas, incluindo o uso do fórceps, ajudaram a dar sustentação à presença masculina nesse contexto e à mudança do local da chegada da vida e do nascer, ampliando o afastamento das mulheres, que estavam majoritariamente envolvidas na cena do parto. Em um campo de força, no tocante à linha hegemônica do saber médico, a mulher seguiu perdendo o protagonismo no processo parturitivo, a interação afetiva e as decisões sobre o seu corpo, tendo em vista que a gravidez e o parto foram tomando o lugar de eventos anatomopatológicos (Leal, et al., 2021, Palharini \& Figueirôa, 2018, Brenes, 1991).

O nascimento, como evento fisiológico, familiar e social, está historicamente associado à arte de partejar, que tem base nas raízes de conhecimento e herança ancestral (Santos, 2016, Santos, 2019), é fruto de saberes e práticas majoritariamente desenvolvidos por mulheres, é mediado pela cultura, ligado a um território, com sistemas de crenças, valores e costumes de um determinado grupo. As parteiras se inserem nesse lugar do partejar pelo conhecimento transmitido oralmente por gerações, com assimilação de experiência, em que o ouvir e observar são acionados pela curiosidade ou pelas necessidades do contexto histórico-social e configuram suas práticas (Gomes, et al., 2016, Oliveira, Peralta \& Sousa, 2019, Pereira, 2016, Cardoso \& Nascimento, 2019).

As parteiras têm uma atuação milenar em práticas cuidadoras, haja vista que os registros da sua atuação remontam aos primórdios da humanidade. Seus cuidados envolviam os assuntos de mulheres, incluindo a gravidez, parto e puerpério e os cuidados com o bebê, como também se dispunham a "aparar e pegar crianças" no cotidiano da vida familiar, privada. Apesar de historicamente ocuparem um campo de tensão e de disputas e seguirem à margem da sociedade, seu saber, que é parte da cultura de um povo, está ancorado na experiência, se preserva, se reconfigura e se atualiza sob influência de gerações (Cruz, 2019).

No Brasil, as parteiras integram ações governamentais e não governamentais para a redução da mortalidade materna, com destaque no ano de 2000 para a implantação do Programa Ministerial Trabalhando com Parteiras Tradicionais (PTPT) no contexto das pactuações dos Objetivos de Desenvolvimento do Milênio (ODM), integrando estratégia para reduzir a mortalidade materna para 35 óbitos por 100 mil nascidos vivos até 2015 (Gusman et al., 2015). O Ministério da Saúde publicou em 2010 documento definindo as diretrizes técnicas e políticas do PTPT para a inclusão do parto domiciliar assistido por parteiras tradicionais no âmbito da atenção básica, com ações para estimular o apoio e a articulação de profissionais e gestores com os serviços locais, em especial com a Estratégia de Saúde da Família (Brasil, 2010). Ainda segundo Gusman et al. (2015), o PTPT atualmente está inscrito no contexto da Rede Cegonha de Atenção à Saúde e muitos são os desafios para essa inserção.

A Rede Cegonha constitui uma estratégia implantada pelo Ministério da Saúde no âmbito do Sistema Único de Saúde (SUS) em 2011, tendo em vista um novo modelo de atenção humanizada, desde o planejamento familiar até os dois primeiros 
anos de vida da criança, voltado para a diminuição da mortalidade materna e neonatal e da violência obstétrica. Apesar de mudanças na direção das boas práticas preconizadas, tanto na gestão quanto na assistência, ainda há desafios diante de práticas intervencionistas e medicalizantes (Lamy, et al., 2021). Assim, experiências relacionadas à falta de diálogo, ao manuseio enrijecido do corpo no que envolve o parto e o nascer, e o maior índice de cesárias do mundo, tendo em vista o recomendado pela Organização Mundial de Saúde (OMS) e a Organização Pan-Americana de Saúde (OPAS), ainda suscitam diálogo sobre a qualidade do cuidado e, consequentemente, atenção à relação com a mortalidade materna (Leal, et al., 2021).

A construção do cuidado a mulheres deve ocorrer em articulação com a diversificada formação cultural da população brasileira, a singularidade dos contextos e, assim, dos conhecimentos que envolvem, por exemplo, etnias distintas dos povos originários e quilombolas. Em algumas áreas do país, em especial nas zonas rurais, ribeirinhas e lugares de difícil acesso, as parteiras tradicionais representam principal acesso à construção da assistência a mulheres e bebês e expressão de apoio e fonte de conforto para além do momento do parto (Santos, 2019, Gomes, et al., 2016, Oliveira, Peralta \& Sousa, 2019). Em outros lugares, têm se apresentado como oferta de cuidado diferenciado. Ou seja, oferta de apoio afetivo, de produção de vínculo.

Neste artigo tomamos como elemento principal a construção de ações e arranjos de parteiras tradicionais que vivem na Região Norte do país, no estado do Amazonas. Esta região é composta por povos indígenas, seringueiros, castanheiros, ribeirinhos e conta com a influência do "fator amazônico" - baixa densidade demográfica, vazios assistenciais, barreiras geográficas com rios, lagos de dimensões continentais, vazantes e cheias dos rios que influenciam a mobilidade das populações que vivem adjacentes à maior floresta tropical e cercadas pela maior bacia hidrográfica do planeta. Nesse território complexo, o modo de cuidar das parteiras tradicionais chama a atenção, e passamos a considerar seus territórios existenciais, que extrapolam o sentido de território geográfico, delimitado fisicamente; são uma construção e estão articulados com os modos de existência e de andar a vida, são "sinônimo de apropriação e subjetivação" (Guattari \& Rolnik, 1986). O que nos leva às seguintes questões: Quais os aspectos constitutivos das ações e arranjos de parteiras tradicionais em uma região amazônica? Considerando que as parteiras tradicionais atuam em seus territórios existenciais o que suas narrativas ofertam para pensar o cuidado em saúde?

Neste estudo, temos como objetivo apresentar as ações e os arranjos de parteiras tradicionais para a conformação do cuidado em uma região amazônica, usando como fio condutor as narrativas das parteiras sobre o contexto do partejar. Tomamos Walter Benjamin (2016) como base teórica e metodológica para a construção das narrativas, empregadas como obra inacabada, artesanal, que têm como objeto a experiência.

\section{Metodologia}

Estudo descritivo de abordagem qualitativa, cujo foco está em investigar a experiência do vivido e envolve a relação entre sujeitos, incluindo suas atitudes e crenças, o que possibilita, por aproximação, uma nova visão do problema (Gil, 2002). Como abordagem qualitativa, ancora-se no pressuposto de que a sociedade é construída por microprocessos, e a realidade social não é um todo unitário, mas "uma multiplicidade de processos sociais que atuam simultaneamente em temporalidades diferentes, compondo, esse sim, uma totalidade" (Victoria et al., 2000, p 39). Assim, investigar ações e arranjos de parteiras tradicionais coaduna-se com este desenho de estudo, que permitiu expor as multiplicidades e composições da realidade amazônica no partejar.

O recurso metodológico da narrativa (Benjamin, 2016) foi utilizado para fazer emergir os momentos privilegiados de intercâmbio de experiências no território de produção intersubjetiva em encontros promovidos pela pesquisa. O referencial de narrativa pauta uma forma de comunicação artesanal que imprime a marca do narrador ao processo de construção, não está 
atrelado à ideia de relatório, e revela um movimento que convoca envolvimento e impressões, permitindo a atualização das práticas (Benjamin, 2016).

O cenário da investigação foi composto por dois municípios no estado do Amazonas, compreendendo a capital e a área rural de um município da região metropolitana. Esses municípios foram escolhidos por integrar o grupo prioritário de implantação da Rede Cegonha no estado (Amazonas, 2011) e por haver concentração de parteiras tradicionais cadastradas pela Coordenação de Saúde da Mulher, da Secretaria Estadual de Saúde.

Participaram do estudo parteiras cadastradas pela Secretaria Estadual de Saúde do Amazonas, cujos critérios de inclusão foram os seguintes: ser parteira residente nos municípios X e Y; ser indicada por trabalhadores da saúde ou por outras parteiras; possuir, no mínimo, três anos de experiência e reconhecer-se como parteira (ou com experiência de). Os critérios de exclusão foram: parteiras indígenas, por partejarem, por vezes, somente em suas aldeias, envolvendo membros da mesma família. Assim, o universo amostral totalizou 15 (quinze) parteiras que atenderam aos critérios. A pesquisa contou com aprovação do Comitê de Ética e Pesquisa sob o no 876.385/2014, junto com o Termo de Consentimento Livre e Esclarecido, em conformidade com a Comissão Nacional de Ética em Pesquisa (CONEP).

A técnica de coleta de dados foi a entrevista e a elaboração de diário de campo (Silva, 2004). As entrevistas foram realizadas no contexto familiar, na casa das parteiras e de mulheres assistidas. A investigação ocorreu nos anos de 2015 a 2016, após mediação inicial feita pela Área Técnica de Saúde da Mulher da Secretaria de Estado do Amazonas. Todas as agendas de encontro foram firmadas em comum acordo com as parteiras quanto a local, dias e horários. As entrevistas contaram com uma forma de abordagem que favoreceu o diálogo e foram gravadas em gravador digital e transcritas na íntegra. Posteriormente, juntou-se o material transcrito com os registros do diário, incluindo as relações e impressões sobre a produção do campo (Silva, 2004). Os encontros foram estreitando as conversas informais, posicionando um estudo que não se vincula à neutralidade do pesquisador. Assim, as narrativas foram validadas no processo de construção do campo (Chagas, 2016).

Para efeito desse artigo, trabalharemos com as narrativas de duas parteiras, uma de cada região investigada. Preservando o anonimato, as parteiras foram nominadas Orquídea e Vitória Régia, nomes fictícios, flores que integram o contexto amazônico e que se caracterizam por rizomas, caules horizontais subterrâneos ou parcialmente aéreos.

Tratamos as narrativas orais gravadas, após transcritas e processadas em composição com o diário de campo, com seus momentos privilegiados advindos das experiências singulares. Uma composição de narrativas inspirada no trabalho de Chagas (2016), organizadas pela ordem dos acontecimentos e não por sua ordem cronológica. Importa para este estudo a ênfase dada ao partejar, tendo em vista que a oralidade faz parte da construção de mundo das parteiras.

Esta investigação integra o estudo multicêntrico sobre Redes de Atenção à Saúde, "Observatório Nacional de Produção de Cuidados em diferentes modalidades à luz do processo de implantação das redes temáticas de atenção à saúde no Sistema Único de Saúde: avalia quem pede, quem faz e quem usa", vigente nos anos de 2014 a 2016, e contempla o estudo de doutorado de uma das autoras.

\section{Resultados}

A pesquisa teve como participantes 15 mulheres, na faixa etária entre 47 e 82 anos, experiência de 20 a 1.250 partejamentos iniciados com as respectivas mães, ou com alguém das suas redes de existência, ou mesmo pela própria necessidade da comunidade. Essas experiências foram vivenciadas em sua maioria em cidades do interior do Amazonas, expostas em narrativas que expressavam e expressam a singularidade amazônica e as multiplicidades que compõem esse território de existência. 
As parteiras, no desenvolvimento das suas atividades, trazem à luz distintos territórios existenciais, onde o partejar compõe campo de potência dos encontros e encadeamento com formação e aprendizagens. As narrativas expressam afetividade e construção de subjetividade entre parteiras e parturientes, a afirmação dos saberes produzidos entre mulheres, a relação natural com o corpo grávido e a construção de autonomia, cuidado e apoio à pessoa que é partejada.

A seguir, as narrativas das parteiras Orquídea e Vitória Régia e, em destaque, o que emergiu apresentando o corpo singular da mulher, os aprendizados e as relações construídas.

Narrativa da parteira Orquídea

O primeiro parto que fiz foi quando já era casada, eu tinha 28 anos. Morava no Seringal, e um dia me acordei, era um senhor me chamando, a mulher dele estava sofrendo e ele foi em busca da parteira. Eu não sabia de nada, só sabia porque vi mamãe, que era parteira, fazer quando meu menino estava para nascer. Fiz tudo direitinho. Quando a parteira chegou, só pegou a criança e cortou o umbigo, eu fiquei olhando para aprender mais. Graças a Deus, deu tudo certinho.

Quando eu observava uma mulher e aquilo dava certo eu seguia prestando atenção. Parteira tem curiosidade de saber, de aprender. Quando queria saber alguma coisa eu perguntava a minha mãe e a minha irmã que também era parteira. No curso que fiz, dentre outras coisas, também aprendi novos nomes e a importância do pré-natal.

Vou pegando na barriga devagarinho e perguntando se está doendo e, se estiver e o bebê está na posição errada, já vou tirando bem devagarinho por fora [vai narrado e mostrando como ajuda a colocar o neném na posição que favorece o parto]. E se for para ter faço o toque devagarinho para ela não ficar inchadinha, pois isso maltrata a mulher e avalio se vai precisar de um hospital, pois vejo se tem dilatação. Eu disse: - Vai ter daqui a uma hora e tal, tem muito tempo. Aí pronto, não fico botando a mão. E, quando faço o toque, é com maior cuidado para não ofender, não maltratar, lá [no hospital] é aquele dedão, aquele cutucão. Tinha tanta vontade de fazer um parto normal na maternidade, para ensinar para as pessoas que estiverem lá comigo, [para] aprenderem. Por mais fácil que esteja sendo o parto, tenho medo, mas é assim mesmo, todas nós passamos por isso. Então, dava aquela maior força para não deixar a mulher esmorecer: - Vai dar tudo certo, a gente sofre e tem dor mesmo. Seu filho já vai nascer, você já vai ficar ali com ele, esquece o medo, será uma alegria para todos nós. Espero, fico por ali, pois parto também é coragem, é confiança.

Quando o neném está para nascer, tem que prestar atenção na saída do ombrinho, para não quebrar a clavícula, porque mesmo que o neném seja grande ele se fecha, acho que Deus ajuda. Nunca quebrei nenhum ombrinho; e nunca perdi uma mulher e nenhum bebê. Quando nasce o bebê ele acha é bom ficar em cima da barriga da mãe, que é bem quentinho, e a placenta vem mais rápido também. Olho o cordão umbilical, se ele ainda está pulsando, porque aquela pulsação é da mãe para o filho, depois que pode cortar. Em cima da mãe, o neném vai logo pegando e mamando. A gente fica muito feliz quando a mãe está bem e a criança também, mas é sempre uma experiência, fico rezando e agradecendo a Deus aquelas vidas.

\section{Narrativa da parteira Vitória Régia}

Fiz o parto de uma senhora, eu já tenho neto de filhos de parto. Não tinha luz, essa mulher morava dentro de um ramal muito longe. Quando ela me chamou, ela falou para mim - Tu se atreves a fazer o meu parto? - Eu não tenho medo, eu gosto de encorajar as mulheres. As minhas parteiras, Dona R foi uma, Dona MA, e eu ouvia delas: - Não esmoreça não. Sempre me encorajaram e assim eu sempre fiz. 
Eu gosto de fazer esse trabalho, não que eu queira tomar a frente de alguém. A mulher tem em parte um pouco de alegria e é um pouco triste saber a dor de ter um filho. Porque nasceu mais uma vida, tanto se alegra o pai e a mãe como a parteira também. Nunca tive estudo, não estudei muito, sou um pouco analfabeta, mas a minha experiência vem de Cristo.

É assim mesmo, cada uma [parteira] tem um dom. A Dona N tem o dom de uma maneira, eu tenho de outra maneira, outra tem de outra maneira e assim nós vamos ajudando as nossas amigas, as nossas colegas, nossas parteiras, mulheres moças igual elas também.

Com um mês já dá para entender se a mulher está grávida ou não. Agora não vai saber se é um homem ou se é uma mulher. Não tinha nenhum material para escutar. Aí, com três meses, você pega na barriga da mulher e dá para escutar se é menino ou menina. Você vai saber se está crescendo no ventre emborcado, se está de barriga pra cima, se ele tá de lado, se ele tá de cabeça no lugar, ou se tá de pé, ou sentado.

Tem a "mãe do corpo", que é como uma bola de carne na barriga que pulsa, parece um coração que pulsa. É uma carne viva, se mexe. Aprendi sobre a "mãe do corpo" com minha mãe, quando estava grávida do meu primeiro filho. Sem a "mãe do corpo", não se engravida. O batimento mais agitado, a mulher está gravida, e mais ainda quando o filho é homem, mulher já é mais lento. Dá para saber só de tocar, de pegar, de escutar a "mãe do corpo".

Às vezes a mulher não quer ir para o hospital pra ter o bebê lá porque ela acha mais confortável em casa, onde elas são mais acariciadas, são mais amadas, né? A parteira é para ver, dar atenção, e ajudar, acompanhar a mulher, fazer aquele carinho, aquele abraço, porque quem está com uma dor é o que quer. Então, temos que fazer isso de aliviar, amar, e junto com aquela mulher sofrer, sentir a dor com ela, e ajudar para que ela fique feliz.

Depois do parto, acompanho a mulher, em especial as que vêm me procurar desde que engravida e que eu também falei do pré-natal, quando precisa de remédio caseiro para ela e para o bebê, e falo também da amamentação, pois é bom para a criança.

\section{Discussão}

Na produção do campo de investigação com parteiras, o recurso metodológico da construção de narrativas (Benjamin, 2016) favoreceu trazer à luz as experiências e identificar os modos de viver e de cuidar apresentados a cada encontro, com as questões que atravessam os contextos socioculturais, dando passagem para a força da oralidade e das experiências coletivas no contexto do partejar. Consideramos que isso só foi possível devido a uma aproximação não atrelada à neutralidade na pesquisa, pois seguimos como pesquisadores in-mundo (Abrahão, et al., 2013), que chegam ao campo levemente preparados e se misturam. Desse modo, tivemos acesso ao que emerge das experiências, sendo esse movimento fundamental para o encontro de corpos e ideias (Deleuze, 2002). Nessa esteira, estão alguns dos estudos com temáticas inseridas na produção do cuidado em saúde (Chagas, 2016, Abrahão, et al., 2013, Santos, et al., 2015).

Da perspectiva de obra inacabada, artesanal, a narrativa não se prende à explicação, ela conserva sua força e permite desdobramentos, pois toma como objeto a experiência (Benjamin, 2016), que neste estudo emerge dos encontros intensivos e extensivos com parteiras, por meio da oralidade que expressa seus arranjos e seu viver. Experiências rizomáticas que trazem das multiplicidades (Deleuze \& Guattari, 2019) apresentando seus descentramentos, linhas de fuga, suas conexões e suas singularidades. Dessa forma, para a análise das narrativas, trabalharemos aqui com dois recortes, considerando o que emergiu nas narrativas com a produção do campo: o corpo singular da mulher, os aprendizados e as relações construídas; e com esse recolhimento, o operador conceitual "singularidade que cuida". 


\section{O corpo singular da mulher, os aprendizados e as relações construídas}

As duas narrativas que apresentamos chamaram a atenção por revelar o lugar central dado à gestante na construção do cuidado (Santos, 2019, Gomes, et al., 2016, Oliveira, Peralta \& Sousa, 2019). Com isso, importa não apenas saber se a mulher faz o pré-natal - questão recorrente nas narrativas das parteiras -, mas também o seu acompanhamento, com quem pode contar, as decisões que implicam o tipo de parto, onde ter o seu bebê e, em ato, o jeito de melhor acomodar a mulher, bem como lhe acomode, para a passagem e segurança do bebê. Uma composição de saberes e práticas e de processos relacionais em que o vínculo e a responsabilização ficam em evidência. Evidência que dialoga com a lógica do parto natural (Arik, et al., 2019), processo fisiológico e simbólico da maternidade, dentro de uma relação que tem a mulher como protagonista e se estabelece a legitimação das experiências.

Estudo internacional (Hoope-Bender, et al., 2014), baseado em evidências nos países de alta, média e baixa rendas se avizinham a esses recolhimentos da pesquisa por demonstrar que as parteiras capacitadas são elo importante de um trabalho coletivo, trazem a lógica do cuidado com responsabilização e a adaptação para atender às necessidades das mulheres, visando também o fortalecimento das suas capacidades, com impacto positivo na redução da mortalidade materna. O referido estudo, também aponta que, quando o foco está nas intervenções e no aumento de cobertura para uma saúde materna e neonatal sob a lógica medicalizante, por vezes a qualidade do cuidado fica negligenciada devido ao abuso, ao desrespeito e ao abandono, sem a cooperação e o fortalecimento das mulheres envolvidas, ausências importantes que não concorrem para a redução da mortalidade materna (Hoope-Bender, et al., 2014).

As parteiras tradicionais seguem com aprendizagens significativas que evidenciam a observação, o cuidado de si e com o outro e a produção de sentidos e significados com as experiências de gravidez, parto e nascimento, bem como o "sentir junto" expressando a delicadeza na construção do cuidado, pois "nasce a mãe e o bebê" e ambos precisam de suporte. Ou seja, as experiências trazidas e produzidas entram em cena agregando sentido e significados que interferem no aprendizado e na prática cuidar (Abrahão \& Merhy, 2014).

Se o receber, o amparar, o ajudar o bebê a vir ao mundo são frequentemente vistos como a atividade fim do processo de gravidez e parto, as parteiras tradicionais nos mostram que o partejar envolve muito mais do que amparar o bebê, envolve partejar também a maternidade na mulher que pare e o cuidado ao corpo. Resgatam-se, aí, a autonomia da mulher e o partejamento, envolvendo o cotidiano da vida no período gravídico, a necessidade da realização do pré-natal, a atenção ao posicionamento do feto e, nas semanas subsequentes ao parto, a disponibilidade em acompanhar a puérpera na preparação de comida, chás e orientar nos cuidados com o bebê. A atenção com as técnicas, a ocupação com o simples e com as relações (Santos, 2019, Gomes, et al., 2016, Oliveira et al., 2019), explicita o amplo e complexo singular olhar para a mulher que pare a si e ao outro. Nesse duplo partejamento pode construir novo ser e estar no mundo, uma vez que é acolhida, cuidada. Com isso, ela tem a possibilidade de elaborar, consciente ou não, suas transformações emocionais e afetivas e, então, fortalecer o entorno social, a cultura e a saúde.

Estes achados do campo de investigação com e entre parteiras tradicionais dão visibilidade às práticas fundadas na transmissão oral que forjam arranjos coletivos de cuidado ao acionar familiares, outras mulheres ou parteiras, compondo redes e lidando com tensões e conquistas no seu contexto sociocultural (Oliveira et al., 2019, Silva et al., 2020). Já os arranjos com o SUS ainda constituem desafios, requer que avancem para além das capacitações com uma construção de apoio e reconhecimento por parte dos gestores (Gusman, 2015), com a construção de redes e vínculos que considerem os modos de viver.

As parteiras tradicionais que participaram do estudo falam da fé, percebem-se portadoras de um “dom” (Pereira, 2016, Cardoso \& Nascimento, 2019) e se esforçam para melhor cumpri-lo. Reconhecem a potência dos corpos das mulheres, e a resistência de suas práticas cuidadoras, que propiciam maior grau de autonomia e liberdade diante das possiblidades que 
configuram o seu agir. Demonstram que o parto natural é o mais cuidadoso para a mulher, alinhando-se ao estudo sobre a expectativa de mulheres no início da gravidez em relação ao parto natural (Arik, et al., 2019). Atentas ao alívio da dor e à segurança do ato, deslocam-se com manejos, técnicas e acomodações, demonstrando atenção em suas decisões e nos aspectos simples do cotidiano, o que expressam em seus arranjos as práticas que vinculam.

Emergiu da investigação que a dimensão cuidadora do agir das parteiras tradicionais, expressa nos encontros e em suas narrativas, dar passagem às variações e as diferenças das mulheres envolvidas, e assim convoca deslocamentos para pensarmos - o que opera o cuidado prestado a mulher pelas mãos de parteiras tradicionais?

\section{A singularidade que cuida como conceito-ferramenta}

Trabalhar as narrativas das parteiras tradicionais, que vai de um dizer a outro dizer, possibilitou refletir sobre a sua presença criativa e cuidadora no encontro com a mulher assistida em todo o processo do partejar - que antecede e extrapola o momento do parto.

As narrativas analisadas apresentaram um modo singular de cuidar que possui uma intencionalidade, mas que não está dado, trata-se de uma produção de subjetividades e de uma construção de vínculo que se dá nos encontros. Esse modo singular apresenta tensionamentos no contexto hegemônico da patologização da gestação e do parto. Tal modo remete à construção de um conceito e suas relações, pois "todo conceito remete a um problema, a problemas pelos quais não teriam sentido, e que só podem ser isolados ou compreendidos na medida de sua solução" (Deleuze \& Guattari, 2010).

Esse modo singular apresentava-se nos encontros e nas narrativas produzidas sobre o partejar e foi o elemento diferencial que nos chamou a atenção, de forma que foi tomado como um operador conceitual por suas conexões com os arranjos de cuidado para cada mulher assistida, levando em conta seus modos de viver. Um conceito vivido como um acontecimento (Deleuze \& Guattari, 2010) que emergiu no contexto do partejar e que tem potência para alargar as possibilidades de cuidado. Esse conceito, "singularidade que cuida", como ferramenta para a análise das narrativas, tanto descreve um desenho teórico quanto é capaz de produzir ação, provocar reflexão, problematizar a nossa dinâmica de vida. Ou seja, tem origem e opera na lógica de um conceito-ferramenta, construção inserida em um contexto (Deleuze \& Guattari, 2010), que se valeu de encontros com e entre parteiras e que tem potência para alargar as possibilidades de cuidado.

Com isso, extraímos, do narrado à dinâmica e a experiência vivida (Chagas, 2016), as ações e os arranjos das parteiras tradicionais que participaram deste estudo. A singularidade é um operador do cuidado no contexto do partejar, como apresentado a seguir.

O encontro da parteira com cada mulher favorece a construção de redes e suportes, na medida em que se interessa pelo que a mulher sente e se desloca para "sentir junto", ajustando o cuidado a conhecimentos e práticas, valorando as experiências, as observações, sem excluir a mulher e seu bebê do centro da cena, e se posicionando nela. Encontros com suas múltiplas conexões existenciais que incrementam o suporte e o vínculo, bem como o andar a vida com autonomia pelos modos de existência (Guattari \& Rolnik, 1986).

O conceito-ferramenta "singularidade que cuida" emerge de uma perspectiva diferenciada da patologização da gravidez e do parto sob a lógica medicalizante, alinha-se à potência dos afetos, que permitem a produção de outros sentidos, conhecimentos e cuidados para os corpos, e que exigem tempo e aproximação, relação de cumplicidade e solidariedade para melhor cuidar e, dessa forma, expandem a biopotência do próprio encontro (Abrahão \& Merhy, 2014).

A "singularidade que cuida" como ferramenta conceitual é uma construção associada a elementos do campo sutil da experiência, da sensibilidade do cuidar por meio de saberes que dialogam, se deslocam, expressando agenciamentos, fluxos que conectam as multiplicidades (Deleuze \& Guattari, 2019), colocam em cena a singularidade do cuidar de forma intensiva, vinculam e se responsabilizam. A "singularidade que cuida" é agenciada pelo mapeamento dos afetos, como um fazer que se 
atualiza pelos territórios de existência. Isso só é possível se desconstruirmos o corpo objetificado e, em relação de alteridade, não nos guiarmos somente pelas regras do campo social, mas para os processos construtores de subjetividade e autonomia nos modos de andar a vida.

\section{Considerações Finais}

Os encontros com parteiras tradicionais e as suas narrativas apontam a construção do vínculo e da cumplicidade nos arranjos - que não estão dados, são sempre uma construção. Encontros com potência para "sentir junto" com abertura para as multiplicidades e a singularidade, possibilitam o protagonismo da parturiente e favorecem extrair novos aprendizados das experiências. Para a construção dos seus arranjos cuidadores no partejar, lançam-se à produção de um encontro singular, um espaço intersubjetivo de troca, sem poupar esforços em acionar técnicas, pessoas e equipamentos necessários para trazer a mulher e o seu bebê ao centro da cena. Assim, importa saber o que a mulher quer, com quem ela conta, criar estratégias para a sua autonomia, para o cuidado de si e para as responsabilidades compartilhadas da sua família.

As narrativas e produções das parteiras envolvidas nesta pesquisa falam de suas ações e arranjos, da singularidade acionada nos encontros de ideias e de corpos, que mobilizam afetos, ressignificam as experiências pelos fluxos que conectam as multiplicidades das mulheres envolvidas. Assim, com a singularidade que emergiu no contexto do partejar, tomamos a "singularidade que cuida" como ferramenta conceitual, como elemento que nos leva a reconhecer os modos de existência, para pensar e operar a singularidade nos processos de cuidar.

A "singularidade que cuida" como conceito-ferramenta, como potência a ser construída e vivida no contexto do cuidado faz pensar e operar novos tipos de arranjos produtores de subjetividades. Estes arranjos se sustentam nos encontros, no que expandem para a composição de redes e para as relações que transitam pelo território dos afetos, marcando um posicionamento de resistência à sujeição dos corpos diante da patologização da gravidez e do parto, da expressão da lógica intervencionista. Desse modo, viabilizam-se processos construtores de autonomia para andar a vida.

Este estudo não se destinou a trazer a produtividade das parteiras, nem a validação do seu saber técnico-científico, que pode configurar o propósito de outros estudos. As investidas nos arranjos produzidos por parteiras de forma intensiva e extensiva, com base em suas narrativas, nos encontros que produzem com as mulheres, acrescentando-se a satisfação demonstrada por estas em se sentirem cuidadas, revelam que a singularidade cuida. Sugere-se que novos estudos sigam pelas múltiplas redes que as parteiras produzem na vida e possam ofertar novos elementos, como o tempo, na lógica do partejar.

Ressaltamos que a perspectiva indígena não foi incluída nesta investigação. A limitação desse estudo está relacionada a não generalização dos seus resultados, tendo em vista que as narrativas não são aferidas como verdade absoluta, mas perspectivas que se referem às experiências de vida e cuidado em um território existencial. Ainda há escassez de estudos que se valem das narrativas considerando a oralidade e a potência constitutiva do viver para pensar arranjos cuidadores.

\section{Referências}

Abrahão, A. L. \& Merhy, E. E. (2014). Formação em saúde e micropolítica: sobre conceitos-ferramentas na prática de ensinar. Interface - Comunicação, Saúde, Educação, 18(49), 313-324.

Abrahão, A. L., Merhy, E. E., Gomes, M. P. C., Tallemberg, C., Chagas, M. S., Rocha, M. et al. (2013). O pesquisador in-mundo e o processo de produção de outras formas de investigação em saúde. Lugar Comum, 39, 133-144.

Amazonas. (2011). Plano Estadual da Rede Cegonha. SUSAM/GCERC.

Arik, R. M., Parada, C. M. G. L., Tonete, V. L. P. \& Sleutjes, F. C. M. (2019). Perceptions and expectations of pregnant women about the type of birth. Revista Brasileira de Enfermagem, 72(3), 41-49.

Benjamin, W. (2016). Sobre o conceito de história. Obras escolhidas I. Brasiliense. 
Brasil. (2010). Ministério da Saúde. Secretaria de Atenção à Saúde. Parto e nascimento domiciliar assistidos por parteiras tradicionais: o Programa Trabalhando com Parteiras Tradicionais e experiências exemplares. Brasília: Ministério da Saúde.

Brenes, A. C. (1991). História da parturição no Brasil, século XIX. Cadernos de Saúde Pública, 7(2), 135-149.

Cardoso, M. A. S. \& Nascimento R. (2019). O dom e a dádiva entre parteiras do Amapá: uma abordagem etnográfica. Saúde e Sociedade, $28(1), 235-249$.

Chagas, M. (2016). Chamei a morte para roda, ela quis dançar ciranda, mudança: estudo descritivo sobre o processo de cuidar da finitude. Rio de Janeiro: Universidade Federal do Rio de Janeiro.

Cruz, Z. V. O. (2019). Ato de partejar: memórias, saberes e práticas de parteiras tradicionais do sudoeste baiano. Vitória da Conquista: Universidade Estadual do Sudoeste da Bahia.

Deleuze G. (2002). Espinosa: Filosofia Prática. Escuta.

Deleuze, G. \& Guattari, F. (2019). Mil Platôs: Capitalismo e Esquizofrenia. 34.

Deleuze, G. \& Guattari F. (2010). O que é filosofia? Ed. 34.

Gil, A. C. (2002). Métodos e técnicas de pesquisa social. (4a ed.), Atlas.

Gomes S. C., Silva, J. A., Oliveira, D. R., Machado, M. F. A. S., Pinheiro, A. K. B. \& Quirino, G. S. (2016). História oral como método para a compreensão do ofício das parteiras. Crato: Universidade Regional do Cariri.

Guattari, F. \& Rolnik, S. (1986). Micropolítica: cartografias do desejo. Vozes.

Gusman, C. R., Viana, A. P. A. L., Miranda, M. A. B., Pedrosa, M. V. \& Villela, W. V. (2015). Inclusão de parteiras tradicionais no Sistema Único de Saúde no Brasil: reflexão sobre desafios. Panam Salud Pública, 37(4/5), 365-70.

Hoope-Bender, P. B. L., Campbell, J., Downe, S., Fauveau, V., Fogstad, H., Homer, C. S., Kennedy, H. P., Matthews, Z., McFadden, A., Renfrew, M. J. \& Van Lerberghe, W. (2014). Improvement of maternal and newborn health through midwifery. Lancet, 384(9949), $1226-35$.

Lamy, Z. C., Gonçalves, L. L. M., Carvalho, R. H. S. B. F., Alves, M. T. S. S. B, Koser, M. E., Martins, M. S., Leal, N. P. \& Thomaz, E. B. A. F. (2021). Atenção ao parto e nascimento em maternidades do Norte e Nordeste brasileiros: percepção de avaliadores da Rede Cegonha. Ciência \& Saúde Coletiva, 26(3), 951-960.

Leal, N. P., Versiane, M. H., Leal, M. C. \& Santos, Y. R. P. (2021). Práticas sociais do parto e do nascer no Brasil: a fala das puérperas. Ciência \& Saúde Coletiva, 26(3), 941-950.

Oliveira, R. S., Peralta, N. \& Sousa M. J. S. (2019). As parteiras tradicionais e a medicalização do parto na região rural do Amazonas. Sexualidad, Salud y Sociedad, 33, 79-100.

Palharini, L. A. \& Figueirôa, S. F. M. (2018). Gênero, história e medicalização do parto: a exposição "Mulheres e práticas de saúde". História, Ciências, Saúde-Manguinhos, 25(4), 1039-1061.

Pereira, M. S. (2016). Association of Traditional Midwives in Maranhão, Brazil: report on assistance during childbirth. Saúde e Sociedade. 25(3):589-601.

Santos, C. (2016). A arte de partejar: o legado das parteiras tradicionais como herança ancestral e os impactos para a saúde das mulheres. https://racismoambiental.net.br/2016/05/10/a-arte-de-partejar-o-legado-das-parteiras-tradicionais-como-heranca-ancestral-e-os-impactos-para-a-saude-dasmulheres

Santos, C. C. (2019). A Cultura do Partejar: Entre a Ancestralidade e a Modernidade. RELACult, 5(1), 1-21.

Santos, C. G., Portugal F. T. A., Silva, M. A. B., Souza, A. C. \& Abrahão, A. L. (2015). Formação em saúde e produção de vínculo: uma experiência PETSaúde na rede de Niterói, RJ, Brasil. Interface - Comunicação, Saúde, Educação, 19(1), 985-993.

Silva, A. L. A. (2004). Produção de subjetividade e gestão em saúde: cartografias da gerência. Campinas: Universidade Estadual de Campinas.

Silva, S. C., Dias-Scopel, R. \& Schweickardt, J. (2020) Gestação e parto em uma comunidade rural amazônica: reflexões sobre o papel da parteira tradicional. Interface - Comunicação, Saúde, Educação, 24.

Victoria, C. G., Knauth, D. R. \& Hassen, M. N. A. (2000). Pesquisa qualitativa em Saúde: uma introdução ao tema. Tomo. 